\title{
Development of 13-Cys-BBR as an Agent Having Dual Action of Anti-Thrombosis and Anti-Inflammation
}

This article was published in the following Dove Press journal:

Drug Design, Development and Therapy

\author{
Guanyu $\mathrm{Li}^{1,2}$ \\ Tong Wang ${ }^{1,2}$ \\ Xiaoyi Zhang ${ }^{1,2}$ \\ Shurui Zhao ${ }^{1,2}$ \\ Yaonan Wang $\mathbb{D}^{1,2}$ \\ Jianhui $\mathrm{Wu} \mathbb{D}^{1,2}$ \\ Shiqi Peng $\mathbb{D}^{1,2}$ \\ Ming Zhaol-3 \\ 'Beijing Area Major Laboratory of Peptide \\ and Small Molecular Drugs, Department of \\ Medicinal Chemistry, School of \\ Pharmaceutical Sciences, Capital Medical \\ University, Beijing 100069, People's \\ Republic of China; ${ }^{2}$ Engineering Research \\ Center of Endogenous Prophylactic of \\ Ministry of Education of China, \\ Department of Medicinal Chemistry, \\ School of Pharmaceutical Sciences, Capital \\ Medical University, Beijing 100069, People's \\ Republic of China; ${ }^{3}$ Beijing Laboratory of \\ Biomedical Materials and Key Laboratory of \\ Biomedical Materials of Natural \\ Macromolecules, Department of \\ Biomaterials, College of Materials Science \\ and Engineering, Beijing University of \\ Chemical Technology, Beijing 100026, \\ People's Republic of China
}

Correspondence: Shiqi Peng; Ming Zhao Department of Medicinal Chemistry, School of Pharmaceutical Sciences, Capital Medical University, NO. 10, Youanmenwaixitoutiao, Fengtai District, Beijing 100069, People's Republic of China Tel +86I0839II528; +86I0839II535 Fax +86I0839II528; +86I0839II533 Email sqpeng@bjmu.edu.cn; maozhao@I26.com
Background: There is a correlation between tumor and inflammation. The activity of 13-[ $\left.\mathrm{CH}_{2} \mathrm{CO}-\mathrm{Cys}(\mathrm{Bzl})-\mathrm{OBzl}\right]$-berberine (13-Cys-BBR) slowing tumor growth is higher than that of BBR. Whether the anti-inflammation activity of 13-Cys-BBR is higher than that of BBR remains unknown. There is a correlation between thrombosis and inflammation. Whether 13-Cys-BBR is an inhibitor of thrombosis remains unknown.

Purpose: The object of this investigation is to compare the activities of 13-Cys-BBR inhibiting thrombosis and inflammation to those of BBR.

Methods: In vivo anti-thrombosis assay was performed on rat model of arterial and venous thrombosis. In vivo anti-inflammation assay was performed on mouse model of xylene induced ear edema.

Results: At oral dose of $66.7 \mathrm{nmol} / \mathrm{kg}, 13-\mathrm{Cys}-\mathrm{BBR}$, but not BBR, inhibited the rats to form both venous thrombus and arterial thrombus. At oral dose of $2 \mu \mathrm{mol} / \mathrm{kg}, 13-\mathrm{Cys}-\mathrm{BBR}$, but not BBR, inhibited the ears of the mice to occur edema.

Conclusion: The anti-venous thrombosis activity, anti-arterial thrombosis activity and antiinflammation activity of 13-Cys-BBR were significantly higher than those of BBR. 13-Cys$\mathrm{BBR}$ is a promising preclinical candidate.

Keywords: berberine, 13-Cys-BBR, thrombosis, inflammation

\section{Introduction}

Berberine (BBR) is a typical representative of the active components of traditional herbs. ${ }^{1}$ BBR exhibited diverse pharmacological actions. In vitro BBR decreased the accumulation of sodium palmitate-induced lipid accumulation, ${ }^{2}$ attenuated the proliferation of tumor cells, ${ }^{3}$ lowed interleukin-2 secretion, ${ }^{4}$ broke the regioselective hydroxylation of estradiol catalyzed by CYP1, ${ }^{5}$ triggered neuronal differentiation, ${ }^{6}$ ended neurodegeneration induced by glutamate, ${ }^{7}$ fragmented DNA double-strand, ${ }^{8}$ regulated the secretion of glucagon like peptide $1,{ }^{9}$ blocked HaCaT cell apoptosis, ${ }^{10}$ inhibited the replication of human cytomegalovirus, ${ }^{11}$ arrested cell cycle, ${ }^{12}$ and inhibited inflammation induced by lipopolysaccharide. ${ }^{13}$ In vivo BBR inhibited the growth and metastasis of endometrial cancer, ${ }^{14}$ inhibited the growth and lung metastasis of hepatocellular carcinoma, ${ }^{15}$ remitted chronic ulcerative colitis, ${ }^{16}$ treated type 2 diabetes, ${ }^{17}$ and managed musculoskeletal disorders (osteoporosis, osteoarthritis and rheumatoid). ${ }^{18}$

However, the poor oral bioavailability seriously limits the clinical utility of BBR. To overcome this shortcoming some preparations, such as the complex of BBR and $\gamma$ cyclodextrin, ${ }^{19}$ the conjugate of BBR and baicalein, ${ }^{20}$ the composition of BBR and 
5-aminosalicylic acid, ${ }^{21}$ as well as the supramolecule dendrimer-BBR, ${ }^{22}$ were well documented. To enhance the antitumor activity the 13-position of $\mathrm{BBR}$ was modified by $\mathrm{CH}_{2}$ CO-Cys(Bzl)-OBzl, $\mathrm{CH}_{2} \mathrm{CO}-\mathrm{Glu}(\mathrm{OBzl})-\mathrm{OBzl}, \mathrm{CH}_{2} \mathrm{CO}-\mathrm{Ile}-$ $\mathrm{OBzl}$ and $\mathrm{CH}_{2} \mathrm{CO}-\mathrm{Asp}(\mathrm{OBzl})-\mathrm{OBzl}$. It was found that $\mathrm{CH}_{2}$ $\mathrm{CO}-\mathrm{Cys}(\mathrm{Bzl})-\mathrm{OBzl}$ modification enhanced the anti-tumor activity of $\mathrm{BBR}$, and the anti-tumor activity of the formed 13-[CH $2 \mathrm{CO}-\mathrm{Cys}(\mathrm{Bzl})-\mathrm{OBzl}]-$ berberine (13-Cys-BBR) was significantly higher than that of $\mathrm{BBR} .^{23}$

As mentioned above, BBR is an inhibitor of inflammation, ${ }^{13}$ but whether the anti-inflammation activity of 13-Cys-BBR is higher than that of BBR remains unknown. It is known that thrombosis and inflammation share common mechanism, but whether 13-Cys-BBR has dual action of anti-thrombosis and anti-inflammation remains unknown. In the context, this investigation is to know whether 13-Cys-BBR has dual action of antithrombosis and anti-inflammation.

\section{Materials and Methods General}

L-Amino acids were commercially purchased from Sigma. All reactions were carried out in nitrogen ( 1 bar). ${ }^{1} \mathrm{H}$ (300 and $800 \mathrm{MHz}$ ) and ${ }^{13} \mathrm{C}(75$ and $200 \mathrm{MHz}) \mathrm{NMR}$ spectra were recorded on Bruker AMX-300 and AMX-800 spectrometers, dimethyl-sulfoxide (DMSO- $\mathrm{d}_{6}$ ) was the solvent and tetramethylsilane was the internal standard. ESI( \pm -FT-ICR -MS spectra were recorded on 9.4 T solariX Fourier transformion cyclotron resonance mass spectrometer (Bruker Corp, Billerica, MA, USA). Chromatographic packing was Sephadex- $\mathrm{LH}_{20}$ or Qingdao silica gel $\mathrm{GF}_{254}$ or Qingdao silica gel $\mathrm{H}_{60}$. Solvents were distilled and dried for use. HPLC was done with Agilent Technologies 1200 Series HPLC system (Agilent Technologies, Santa Clara, CA, USA) on Eclipse XDB C18 column ( $5 \mu \mathrm{m}, 4.6 \mathrm{~mm} \times$ $150 \mathrm{~mm}$ ); column temperature: $40^{\circ} \mathrm{C}$; mobile phase: water and methanol; gradient: 60\% methanol (0-5 min), 70\% methanol (5-10 $\mathrm{min}), 80 \%$ methanol (10-20 $\mathrm{min})$ and $90 \%$ methanol (20-30 $\mathrm{min})$; flow rate: $0.8 \mathrm{~mL} / \mathrm{min}$; ultraviolet (UV) absorption spectrum was recorded online; UV detector was set to a scanning range of $200-400 \mathrm{~nm}$; the chromatogram was monitored at a wavelength of $280 \mathrm{~nm}$.

\section{Animals}

Male ICR mice and male Sprague Dawley rats (AEEI2019-179) were purchased from the Laboratory Animal Center of Capital Medical University. The protocol of the evaluations was reviewed and approved by ethics committee of Capital Medical University. Animal welfare fulfilled the requirements of Animal Welfare Act and NIH Guide for Care and Use of Laboratory Animals.

Statistical analysis and multiple group comparison were performed with ANOVA and LSD, respectively. SPSS 19.0-program was used to address $P$-value, and the value less than 0.05 was considered statistically significant.

\section{Chemistry}

Synthetic Route to 13-Cys-BBR

To practice the development of 13-Cys-BBR a procedure consisted of 4-step reactions was used (Figure 1). In contrast to 3 directly coupling $\mathrm{Cys}(\mathrm{Bzl})-\mathrm{OBzl},{ }^{23}$ here the activated ester of $\mathrm{N}$-hydroxysuccinimide of 3 coupled Cys(Bzl)-OBzl. This led to a substantial increase of the yield of 13-Cys-BBR, and will benefit preparing sample of preclinical investigation. Figure 1 indicates that the activated ester of $\mathrm{N}$-hydroxysuccinimide in the square brackets is not isolated, and the corresponding UV/Vis, FTIR, HRMS, ${ }^{1} \mathrm{H}$ NMR and ${ }^{13} \mathrm{C}$ NMR spectra were not measured.

\section{Preparation of 7,8-Dihydro-8- $\mathrm{CH}_{2} \mathrm{COCH}_{3}$ -}

\section{Berberine (I)}

In to a solution of $5 \mathrm{~g}(13.6 \mathrm{mmol})$ of BBR in $26 \mathrm{~mL}$ of aqueous $\mathrm{NaOH}(5 \mathrm{M}) 5 \mathrm{~mL}$ of acetone was added dropwise (within $20 \mathrm{~min}$ ) and stirred at room temperature for $34 \mathrm{~h}$. Then, this mixture was stirred at $0^{\circ} \mathrm{C}$ and adjusted to pH 7 by adding hydrochloric acid $(10 \mathrm{M})$. The mixture was filtered to collect the precipitates. After washing with water $4.88 \mathrm{~g}(85 \%)$ of 1 was obtained.

\section{Preparation of $13-\mathrm{CH}_{2} \mathrm{CO}_{2} \mathrm{C}_{2} \mathrm{H}_{5}$-Berberine (2)}

A solution of $4 \mathrm{~g}(9.3 \mathrm{mmol})$ of $1,1.4 \mathrm{~mL}$ of ethyl bromoacetate, $120 \mathrm{mg}$ of $\mathrm{NaI}$ and $100 \mathrm{~mL}$ of acetonitrile was stirred at $85^{\circ} \mathrm{C}$ for $64 \mathrm{~h}$. The reaction mixture was cooled to room temperature and filtered. The filtrate was evaporated in vacuum, the residue was purified on a column of silica gel $\left(\mathrm{CH}_{2} \mathrm{Cl}_{2} / \mathrm{MeOH}, 15 / 1\right)$ to give 3.56 $\mathrm{g}(83 \%)$ of 2 as yellow powders. $\operatorname{ESI}(+) / \mathrm{MS}(\mathrm{m} / \mathrm{e}): 422$ $[\mathrm{M}-\mathrm{Br}]{ }^{+}{ }^{1} \mathrm{H}$ NMR (DMSO-d $\left.6,300 \mathrm{MHz}\right) \delta / \mathrm{ppm}=10.021$ $(\mathrm{s}, 1 \mathrm{H}), 8.254(\mathrm{~d}, J=9.6 \mathrm{~Hz}, 1 \mathrm{H}), 8.015$ (d, $J=9.6 \mathrm{~Hz}, 1$ $\mathrm{H}), 7.187(\mathrm{~s}, 1 \mathrm{H}), 7.097(\mathrm{~s}, 1 \mathrm{H}), 6.696(\mathrm{~s}, 2 \mathrm{H}), 4.436(\mathrm{~s}$, $2 \mathrm{H}), 4.238\left(\mathrm{dd}, J_{1}=7.2 \mathrm{~Hz}, J_{2}=13.8 \mathrm{~Hz}, 2 \mathrm{H}\right), 4.116(\mathrm{~s}$, $3 \mathrm{H}), 4.093$ (s, 3H), 3.120 (t, $J=7.2 \mathrm{~Hz}, 2 \mathrm{H}), 1.266$ (t, $J=$ $13.8 \mathrm{~Hz}, 3 \mathrm{H})^{23}$ 


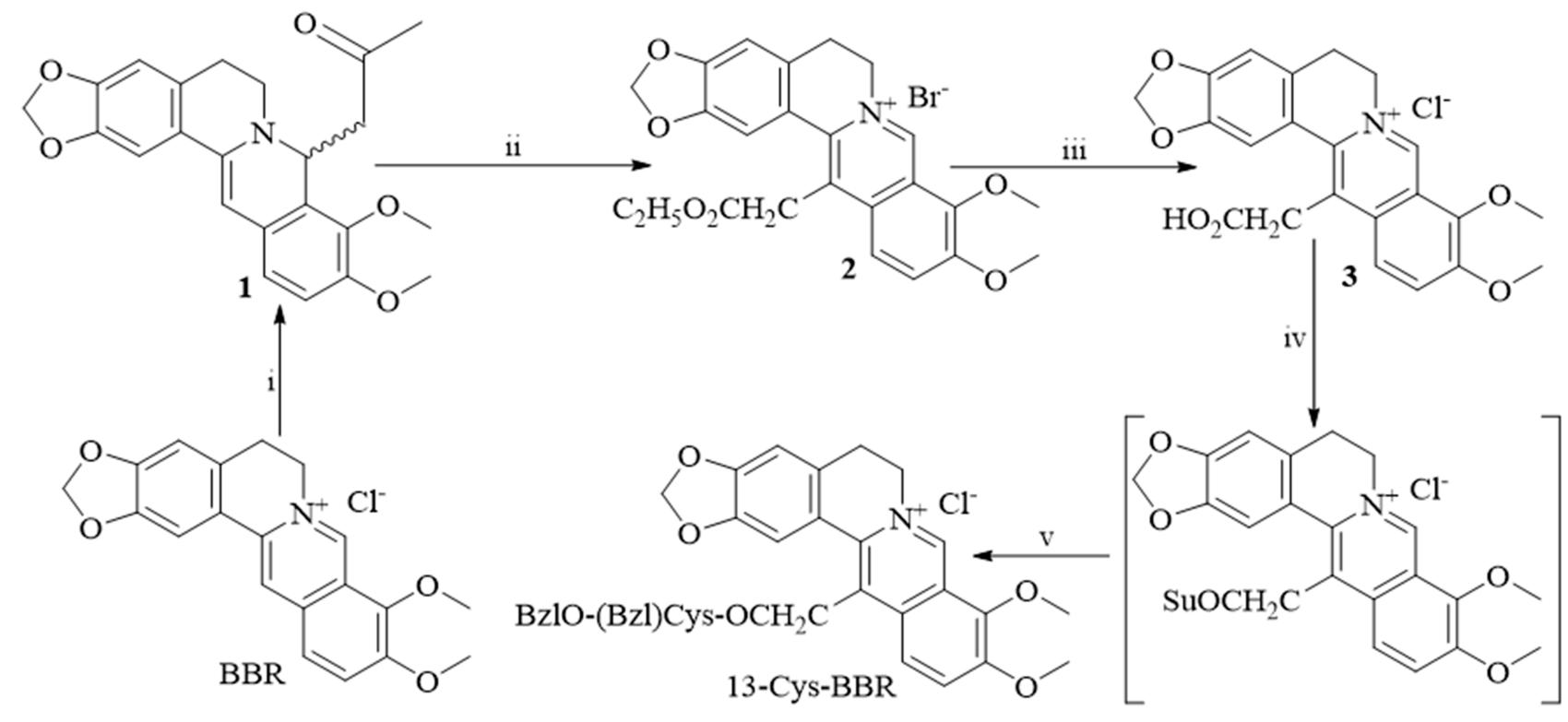

Figure I Improved synthetic route to I3-Cys-BBR: (i) aqueous $\mathrm{NaOH}(5 \mathrm{M})$, acetone, 3 hours and room temperature; (ii) ethyl bromoacetate, $\mathrm{Nal}$, $\mathrm{CH} \mathrm{C}_{3} \mathrm{CN}, 6$ hours and 80 ${ }^{\circ} \mathrm{C}$; (iii) methanol $\mathrm{NaOH}(2 \mathrm{M}), \mathrm{HCl}, \mathrm{I} 0$ hours, rt; (iv) N-hydroxysuccinimide (HOSu), dicyclohexylcarbodiimide (DCC) and HBTu; (v) Cys(Bzl)-OBzl, N-methylmorpholin, 48 hours and room temperature.

Abbreviations: BBR, berberine; I3-Cys-BBR, I3-[C $\left.\mathrm{CH}_{2} \mathrm{CO}-\mathrm{Cys}(\mathrm{Bzl})-\mathrm{OBz} \mid\right]-$ berberine.

\section{Preparation of $13-\mathrm{CH}_{2} \mathrm{CO}_{2} \mathrm{H}$-Berberine (3)}

At room temperature and with stirring into a solution of $3.56 \mathrm{~g}(7.7 \mathrm{mmol})$ of $2,5 \mathrm{~mL}$ of methanol and $2 \mathrm{~mL}$ of aqueous $\mathrm{NaOH}(2 \mathrm{M})$ was added dropwise, the $\mathrm{pH}$ of the reaction mixture was kept 13 , and TLC $\left(\mathrm{CH}_{2} \mathrm{Cl}_{2} / \mathrm{MeOH}\right.$, 10/1) indicated the complete disappearance of 2 . The reaction mixture was evaporated in vacuum, and with dilute hydrochloric acid the $\mathrm{pH}$ of the residue was adjusted to 3 to form precipitates. The precipitates were collected by filtration to give $3.02 \mathrm{~g} \mathrm{(91 \% )} \mathrm{of} 3$ as yellow powders. ESI $(+) / \mathrm{MS}(\mathrm{m} / \mathrm{e}): 394[\mathrm{M}-\mathrm{Cl}]^{+}{ }^{1} \mathrm{H}$ NMR(DMSO-d 6,300 $\mathrm{MHz}) \delta / \mathrm{ppm}=10.040(\mathrm{~d}, J=9 \mathrm{~Hz}, 1 \mathrm{H}), 8.254\left(\mathrm{dd}, J_{1}=9\right.$ $\left.\mathrm{Hz}, J_{2}=9.6 \mathrm{~Hz}, 1 \mathrm{H}\right), 8.014\left(\mathrm{dd}, J_{1}=9 \mathrm{~Hz}, J_{2}=15 \mathrm{~Hz}, 1\right.$ H), 7.195 (d, $J=15 \mathrm{~Hz}, 2 \mathrm{H}), 6.192$ (s, $2 \mathrm{H}), 4.817$ (s, 2 H), 4.483 (s, $1 \mathrm{H}), 4.357(\mathrm{~s}, 1 \mathrm{H}), 4.114(\mathrm{~s}, 3 \mathrm{H}), 4.088$ (s, $3 \mathrm{H}), 3.112(\mathrm{~s}, 2 \mathrm{H}){ }^{23}$

\section{Preparation of I3-[CH $\left.{ }_{2} \mathrm{CO}-\mathrm{Cys}(\mathrm{Bz})-\mathrm{OBzl}\right]-$ Berberine (13-Cys-BBR)}

At room temperature a solution of $860 \mathrm{mg}(2 \mathrm{mmol})$ of 3 , $250 \mathrm{mg}(2.2 \mathrm{mmol})$ of HOSu, $440 \mathrm{mg}(2.1 \mathrm{mmol})$ of DCC, and $2 \mathrm{~mL}$ of $\mathrm{N}$-methylmethane-sulfonamide in $4 \mathrm{~mL}$ of tetrahydofuran was stirred, the $\mathrm{pH}$ was adjusted to 7 by $\mathrm{N}$-methylmorpholine, and stirred for $8 \mathrm{~h}$. Into the reaction mixture $676 \mathrm{mg}(2 \mathrm{mmol})$ of Cys(Bzl)-OBzl was added and stirred for another $16 \mathrm{~h}$. The reaction mixture was evaporated in vacuum and the residue was purified on silica gel column $\left(\mathrm{CH}_{2} \mathrm{Cl}_{2} / \mathrm{MeOH}, 100 / 1\right)$ to give $978 \mathrm{mg}$ (69\%) of 13-Cys-BBR as yellow powders. FT-ICR-MS (m/e): $677.23418[\mathrm{M}-\mathrm{Cl}]^{+}$(calculated value: 677.2316). ${ }^{1} \mathrm{H}$ NMR (DMSO-d 6 , $\left.800 \mathrm{MHz}\right): \delta / \mathrm{ppm}=9.971(\mathrm{~s}, 1 \mathrm{H})$, $9.312(\mathrm{~d}, J=7.2 \mathrm{~Hz}, 1 \mathrm{H}), 7.974(\mathrm{~s}, 2 \mathrm{H}), 7.599$ (s, $1 \mathrm{H})$, 7.408 (s, $5 \mathrm{H}), 7.247$ (s, $5 \mathrm{H}), 7.172(\mathrm{~s}, 1 \mathrm{H}), 6.152$ (s, 2 H), 5.189 (s, 2 H), 4.849 (m, $1 \mathrm{H}), 4.723$ (m, $1 \mathrm{H}), 4.303$ (s, $2 \mathrm{H}), 4.103(\mathrm{~s}, 3 \mathrm{H}), 4.018(\mathrm{~s}, 3 \mathrm{H}), 3.805(\mathrm{~s}, 2 \mathrm{H})$, 3.106 (m, $2 \mathrm{H}), 2.927$ (m, $3 \mathrm{H}) .{ }^{13} \mathrm{C}$ NMR (DMSO-d 6,200 $\mathrm{MHz}), \delta / \mathrm{ppm}=170.7,170.4,150.8,149.9,147.3,145.9$, $144.7,138.4,137.9,136.2,134.5,133.4,129.4,128.9$, $128.4,128.5,128.2,127.8,127.4,126.3,121.5,121.4$, $120.5,109.7,108.9,102.5,66.9,65.4,62.5,57.5,57.4$, $52.3,37.7,35.6,32.6,27.7$. HPLC purity: $98.3 \%{ }^{23}$

\section{Bioassays}

\section{In vivo Anti-Inflammatory Assay}

Male ICR mice $(25 \pm 2 \mathrm{~g})$ were housed in a 12/12 light/ dark cycle $\left(21 \pm 2^{\circ} \mathrm{C}\right)$ for 2 days before use. Food and water were supplied ad libitum. The mice were randomly divided into $0.5 \%$ CMC-Na group (blank control), BBR group (parent compound control, oral dose: $2 \mu \mathrm{mol} / \mathrm{kg}$ ), 13-Cys-BBR group (oral dose: $2 \mu \mathrm{mol} / \mathrm{kg}$ ) and aspirin group (positive control, oral dose: $1100 \mu \mathrm{mol} / \mathrm{kg}$ ), each 9 mice. Thirty min later $0.03 \mathrm{~mL}$ of xylene was evenly applied to the anterior and posterior surfaces of the right ear of the mice, while the left ear was reserved as 
a control. $2 \mathrm{~h}$ later the mice were weighed, sacrificed by ether anesthesia to collect blood and remove ears. A rubber plug punch of $7 \mathrm{~mm}$ aperture was used to take the circular sections of the ears for weigh. Xylene induced ear edema was represented by the difference in weight of xylene treated right ear section and xylene untreated left ear section.

\section{Measuring Serum TNF- $\alpha$ of Ear Edema Mice}

Into $50 \mu \mathrm{L}$ of aqueous sodium citrate (3.8\%) $450 \mu \mathrm{L}$ of blood was added, which were collected from inflammatory mice treated by CMC-Na (blank control) or BBR (parent compound control, oral dose: $2 \mu \mathrm{mol} / \mathrm{kg}$ ) or 13-Cys-BBR (oral dose: $2 \mu \mathrm{mol} / \mathrm{kg}$ ) or aspirin group (positive control, oral dose: $1100 \mu \mathrm{mol} / \mathrm{kg}$ ). The anti-coagulated blood was centrifuged at $200 \mathrm{~g}$ for $20 \mathrm{~min}$ to get the serum, and the TNF- $\alpha$ in the serum was measured according to the specification of mouse TNF- $\alpha$ ELISA kit (Xitang Biotechnology Co., Shanghai, People's Republic of China).

\section{Arterial Thrombus Weight Assay}

Arterial thrombus weight was used to represent the antiarterial thrombotic activity and measured on Sprague Dawley rat model (male, 240-270 g, each 10) by following the procedure of the literature. ${ }^{25}$ In this assay $0.5 \%$ CMC-Na (blank control, oral dose: $10 \mathrm{~mL} / \mathrm{kg}$ ) or a suspension of aspirin in $0.5 \% \mathrm{CMC}-\mathrm{Na}$ (positive control, oral dose: $167 \mu \mathrm{mol} / \mathrm{kg}$ ) or a suspension of 13-Cys-BBR in $0.5 \%$ CMC-Na (oral dose: $66.7 \mathrm{nmol} / \mathrm{kg}$ ) or a suspension of BBR in $0.5 \%$ CMC-Na (parent compound control, oral dose: $66.7 \mathrm{nmol} / \mathrm{kg}$ ) were given to the rats. $30 \mathrm{~min}$ after oral administration the rat was anaesthetized with sodium pentobarbital $(80.0 \mathrm{mg} / \mathrm{kg}$, ip), then the right carotid artery and left jugular vein of the rat were separated. A polyethylene tube having an exactly weighted thread (6 $\mathrm{cm}$ in length) was filled by the solution of heparin sodium in NS $(50 \mathrm{IU} / \mathrm{mL})$. One end of this polyethylene tube was inserted into the left jugular vein and another end of this polyethylene tube was inserted into the right carotid artery. Prior to this procedure the anticoagulant (heparin sodium) was injected, and then the blood was allowed through the polyethylene tube to flow for $15 \mathrm{~min}$. Finally, the thread inside the polyethylene tube was taken out to weigh, and the increased weight of the thread was calculated.

\section{Venous Thrombus Weight Assay}

Venous thrombus weight was used to represent the anti-venous thrombotic activity and measured on Sprague Dawley rat model (male, 240-270 g, each 12) by following the procedure of the literature. ${ }^{25}$ Inferior vena cava (IVC) ligation model was used to evaluate the activity. In brief, rats were orally given $0.5 \%$ CMC-Na (blank control, oral dose: $10 \mathrm{~mL} / \mathrm{kg}$ ) or a suspension of warfarin in $0.5 \% \mathrm{CMC}-\mathrm{Na}$ (positive control, oral dose: $4870 \mathrm{nmol} / \mathrm{kg}$ ) or a suspension of 13-Cys-BBR in $0.5 \%$ CMC-Na (oral dose: $66.7 \mathrm{nmol} / \mathrm{kg}$ ) or a suspension of BBR in $0.5 \%$ CMC-Na (parent compound control, oral dose: $66.7 \mathrm{nmol} / \mathrm{kg}$ ). $30 \mathrm{~min}$ after the administration the rats were anaesthetized with sodium pentobarbital $(80.0 \mathrm{mg} / \mathrm{kg}$, ip), and then a midline laparotomy was performed. From the body cavity, the small bowel was exteriorized and slightly moved to the left of the animal surrounding moistened gauze to separate the infrarenal IVC. With braided black silk suture of $4 / 0$, the junction of the IVC and left renal vein on the IVC were ligated. The warm saline was sprayed, into the abdominal cavity the tissues were back set, with braided black silk suture of $4 / 0$ the muscle layer and skin were gradually sutured. 4 $\mathrm{h}$ later the abdominal cavity was cut again. The ligatures were made near the bifurcation of the IVC and around all side branches of the ligated IVC segment. Consequently, $2 \mathrm{~cm}$ of venous segment bellow the ligation site was excised, the thrombus was removed, the blood was blotted with filter paper, and the thrombus was weighed to represent the activity.

\section{Measuring Serum P-Selectin of Venous Thrombosis Rats}

The blood of the rats treated by $0.5 \%$ CMC-Na (blank control, oral dose: $10 \mathrm{~mL} / \mathrm{kg}$ ) or a suspension of warfarin in $0.5 \%$ CMC-Na (positive control, oral dose: $4870 \mathrm{nmol} / \mathrm{kg}$ ) or a suspension of $13-\mathrm{Cys}-\mathrm{BBR}$ in $0.5 \% \mathrm{CMC}-\mathrm{Na}$ (oral dose: $66.7 \mathrm{nmol} / \mathrm{kg}$ ) or a suspension of BBR in $0.5 \% \mathrm{CMC}-\mathrm{Na}$ (parent compound control, oral dose: $66.7 \mathrm{nmol} / \mathrm{kg}$ ) was collected into a tube containing 3.8\% aqueous sodium citrate at a ratio of 9 parts aqueous sodium citrate to 1 part blood. The blood was immediately centrifuged at $1000 \mathrm{rpm}$ for $15 \mathrm{~min}$. The top layer was collected as the platelet-rich plasma (PRP), and received 10-fold-dilution with diluents solution from the kit of rat P-selectin ELISA kit (Cusabio, Biotech, USA) to get PRP sample. Serum P-selectin of the blood was measured by use of the kit. The wells containing $980 \mu \mathrm{L}$ of PRP from the blood were at $37^{\circ} \mathrm{C}$ incubated for $120 \mathrm{~min}$. After removing solvent, into each well $100 \mu \mathrm{L}$ of biotin labeling antibody (from the kit) was added and at $37^{\circ} \mathrm{C}$ incubated for $60 \mathrm{~min}$. The solution in the well was discarded, by adding $200 \mu \mathrm{L}$ of washing solution (from the kit) the well was washed for three times, into each well $100 \mu \mathrm{L}$ of horseradish peroxidase labeling avidin (from the kit) was added, at $37^{\circ} \mathrm{C}$ incubated for $60 \mathrm{~min}$, 
and then washed with washing solution (from the kit) for five times. For coloration, into each well $90 \mu \mathrm{L}$ of the substrate solution (from the kit) were added and then in dark at $37^{\circ} \mathrm{C}$ incubated for $20 \mathrm{~min}$. To stop the reaction into each well $50 \mu \mathrm{L}$ of the stop solution (from the kit) was added. The OD value of the well was measured at $450 \mathrm{~nm}$ within $15 \mathrm{~min}$. P-Selectin level was calculated by using the standard curve (from the kit standard samples).

\section{Investigation of Docking Towards P-Selectin}

To compare the feature of 13-Cys-BBR and BBR in the active sire of $\mathrm{P}$-selectin the docking investigation was performed by using the procedure of the literature. ${ }^{25}$ In brief, the conformations of 13-Cys-BBR and BBR (parent compound control) were generated and energy-optimized. Ten energy-optimized conformations of BBR and 13-Cys-BBR were selected and individually docked into the active site of P-selectin by using CDOCKER protocol to get docking scores.

\section{ESI(+)-FT-ICR-MS Analysis of Homogenate Extracts}

To examine thrombus targeting action of 13-Cys-BBR the homogenate extracts of the thrombus, blood, brain, heart, kidney, liver and spleen of the arterial thrombosis rats treated by CMC-Na (blank control) or 13-Cys-BBR, as well as the venous thrombosis rats treated by CMC-Na or 13-Cys-BBR were homogenized. The homogenates were extracted with methanol and the extracts received ESI (+)-FT-ICR-MS analysis. ${ }^{24}$

\section{Results and Discussion}

\section{The Improvement of Synthetic Route Increased the Yield of I3-Cys-BBR}

By coupling Cys(Bzl)-OBzl with active ester of 3, i.e.13$\mathrm{CH}_{2} \mathrm{CO}_{2} \mathrm{Su}$-berberine, but not 3 itself, the synthetic route of the literature was improved. The improvement of the synthesis increased the yield of 13-Cys-BBR from previous 32\% to present $69 \%$. Therefore, this synthetic route is better than that of the literature, ${ }^{23}$ and is good enough for providing 13Cys-BBR to receive preclinical investigations.

\section{The Anti-Inflammation Activity of 13-Cys-BBR Is Higher Than That of BBR}

The anti-inflammatory activities of 13-Cys-BBR and BBR (parent compound control) were assayed on ear edema mice. In the assay CMC-Na was used as the blank control and aspirin was used as the positive control. Figure 2A shows that 13-Cys-BBR, but not BBR, orally inhibits the ear edema of the mice. The activity of $2 \mu \mathrm{mol} / \mathrm{kg}$ of $13-$ Cys-BBR is equal to that of $1100 \mu \mathrm{mol} / \mathrm{kg}$ of aspirin. Thus, the anti-inflammatory activity of 13-Cys-BBR is not only higher than that of BBR but also is 550 times of aspirin.

\section{3-Cys-BBR Effectively Decreases Serum TNF- $\alpha$ of Ear Edema Mice}

The serum TNF- $\alpha$ of ear edema mice treated by 13-CysBBR and BBR (parent compound control) was tested with ELISA kit. In this assay CMC-Na was used as the blank control and aspirin was used as the positive control. Figure $2 \mathrm{~B}$ shows that the serum TNF- $\alpha$ of the mice orally treated by $2 \mu \mathrm{mol} / \mathrm{kg}$ of 13 -Cys-BBR, but not $\mathrm{BBR}$, is significantly lower than that of the mice treated by $\mathrm{CMC}-\mathrm{Na}$, and is equal to that of the mice treated by $1100 \mu \mathrm{mol} / \mathrm{kg}$ aspirin. Therefore, the efficacy of 13-CysBBR decreasing serum TNF- $\alpha$ is significantly higher than that of BBR and is 550 times of aspirin.

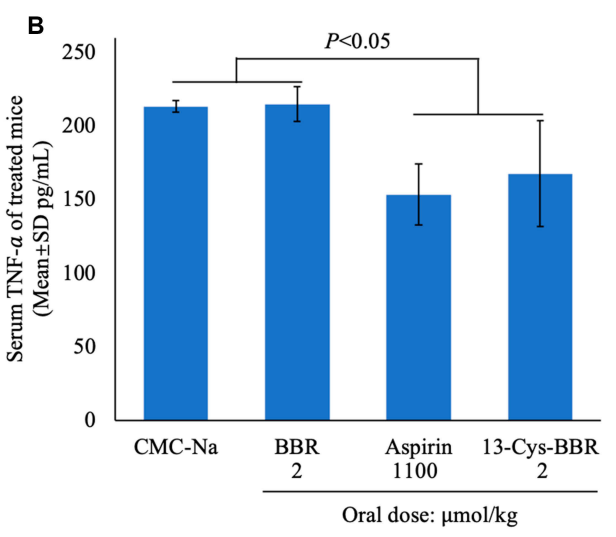

Figure 2 Effect of I3-Cys-BBR on ear edema and serum TNF- $\alpha$ : (A) effect of I3-Cys-BBR on ear edema; (B) effect of I3-Cys-BBR on serum TNF- $\alpha$ of ear edema mice; $n=9$. Abbreviations: BBR, berberine; I3-Cys-BBR, I3-[CH $\mathrm{CH}_{2} \mathrm{CO}-\mathrm{Cys}(\mathrm{Bzl})-\mathrm{OBz}$ ] - -berberine. 


\section{The Anti-Venous Thrombosis Activity of} 13-Cys-BBR Is Higher Than That of BBR

The anti-venous thrombosis activities of 13-Cys-BBR and BBR (parent compound control) were assayed on rat model. Figure $3 \mathrm{~A}$ shows that the weight of the venous thrombus of the rats orally treated by $66.7 \mathrm{nmol} / \mathrm{kg}$ of 13Cys-BBR, but not BBR, is significantly lower than that of the rats orally treated by CMC-Na (blank control) and is equal to that of the rats orally treated by $4.87 \mu \mathrm{mol} / \mathrm{kg}$ of warfarin (positive control). Therefore, the anti-venous thrombosis activity of 13-Cys-BBR is significantly higher than that of BBR, and is 73 times of warfarin.

\section{The Anti-Arterial Thrombosis Activity of 13-Cys-BBR Is Higher Than That of BBR}

The anti-arterial thrombosis activities of 13-Cys-BBR and BBR (parent compound control) were assayed on rat model. Figure 3B shows that the weight of the arterial thrombus of the rats orally treated by $66.7 \mathrm{nmol} / \mathrm{kg}$ of $13-C y s-B B R$, but not BBR, is significantly lower than those of the rats orally treated by CMC-Na (blank control) and aspirin (positive control, oral dose: $16.7 \mu \mathrm{mol} / \mathrm{kg}$ ). Therefore, the antiarterial thrombosis activity of 13-Cys-BBR is significantly higher than that of BBR, and is more than 250 times of aspirin.

\section{3-Cys-BBR Effectively Decreases Serum P-Selectin of Venous Thrombosis Rats}

The serum P-selectin of venous thrombosis rats treated by 13-Cys-BBR and BBR (parent compound control) was tested with ELISA kit. Figure $3 \mathrm{C}$ shows that the serum
P-selectin of the rats orally treated by $66.7 \mathrm{nmol} / \mathrm{kg}$ of 13 Cys-BBR, but not BBR, is significantly lower than that of the rats orally treated by CMC-Na (blank control), and is equal to that of the rats orally treated by $4.87 \mu \mathrm{mol} / \mathrm{kg}$ of warfarin (positive control). Therefore, the efficacy of 13Cys-BBR decreasing serum P-selectin is significantly higher than that of BBR and is 73 times of warfarin.

\section{The Active Site of P-Selectin Is Suitable for I3-Cys-BBR, but Not BBR}

The docking investigation of 13-Cys-BBR and BBR (parent compound control) disclosed that the score of the former (docking score: 160.26) was higher than that (docking score: 103.16) of the latter (Figure 4). In addition, the interactions of 13-Cys-BBR and the amino acid residues of the active site are more than those of BBR and the amino acid residues of the active site (see the locally amplified illustrations of Figure 4). These distinct interactions suggest that the active site of P-selectin is suitable for 13-Cys-BBR, but not BBR, and all biological advantages of the former to the latter could be attributed to the interactions of P-selectin with them. It was well documented that the anti-thrombotic agent down-regulating the expression of P-selectin, thereby decreasing serum P-selectin and inhibiting both venous and arterial thrombosis. ${ }^{25}$ Thus, the docking investigation theoretically explains why the venous thrombus weight and the serum P-selectin of the rats treated by 13-Cys-BBR are lower than those of the rats treated by BBR. The docking investigation also explains why at $66.7 \mathrm{nmol} / \mathrm{kg}$ of oral dose 13-Cys-BBR, but not BBR, is able to inhibit the rats to form arterial thrombus and venous thrombus.
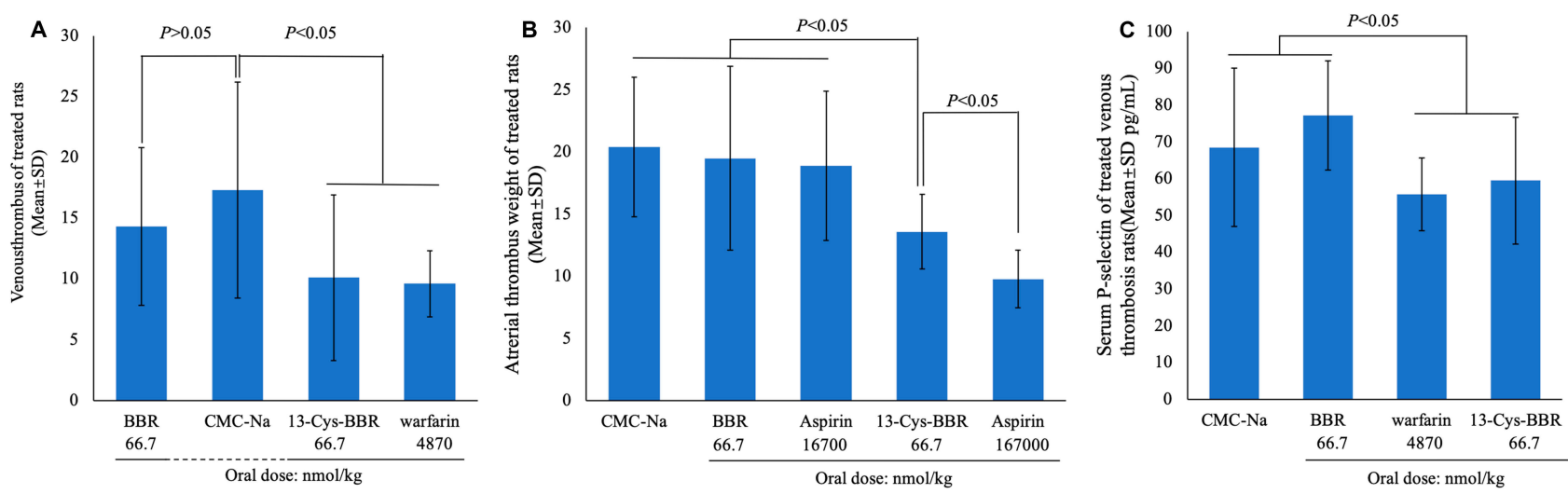

Figure 3 Effect of I3-Cys-BBR and BBR on thrombosis and P-selectin in vivo: (A) anti-venous thrombosis activity of $66.7 \mathrm{nmol} / \mathrm{kg}$ of oral I3-Cys-BBR and BBR, $\mathrm{n}=10$; (B) anti-arterial thrombosis activity of $66.7 \mathrm{nmol} / \mathrm{kg}$ of oral $13-\mathrm{Cys}-\mathrm{BBR}$ and BBR, $\mathrm{n}=10$; (C) inhibition of $66.7 \mathrm{nmol} / \mathrm{kg}$ of oral $13-\mathrm{Cys}-\mathrm{BBR}$ and BBR to P-selectin in the serum of treated rats in venous thrombosis assay, $n=10$.

Abbreviations: BBR, berberine; I3-Cys-BBR, I3-[CH$\left.{ }_{2} \mathrm{CO}-\mathrm{Cys}(\mathrm{Bzl})-\mathrm{OBz} \mid\right]$-berberine. 


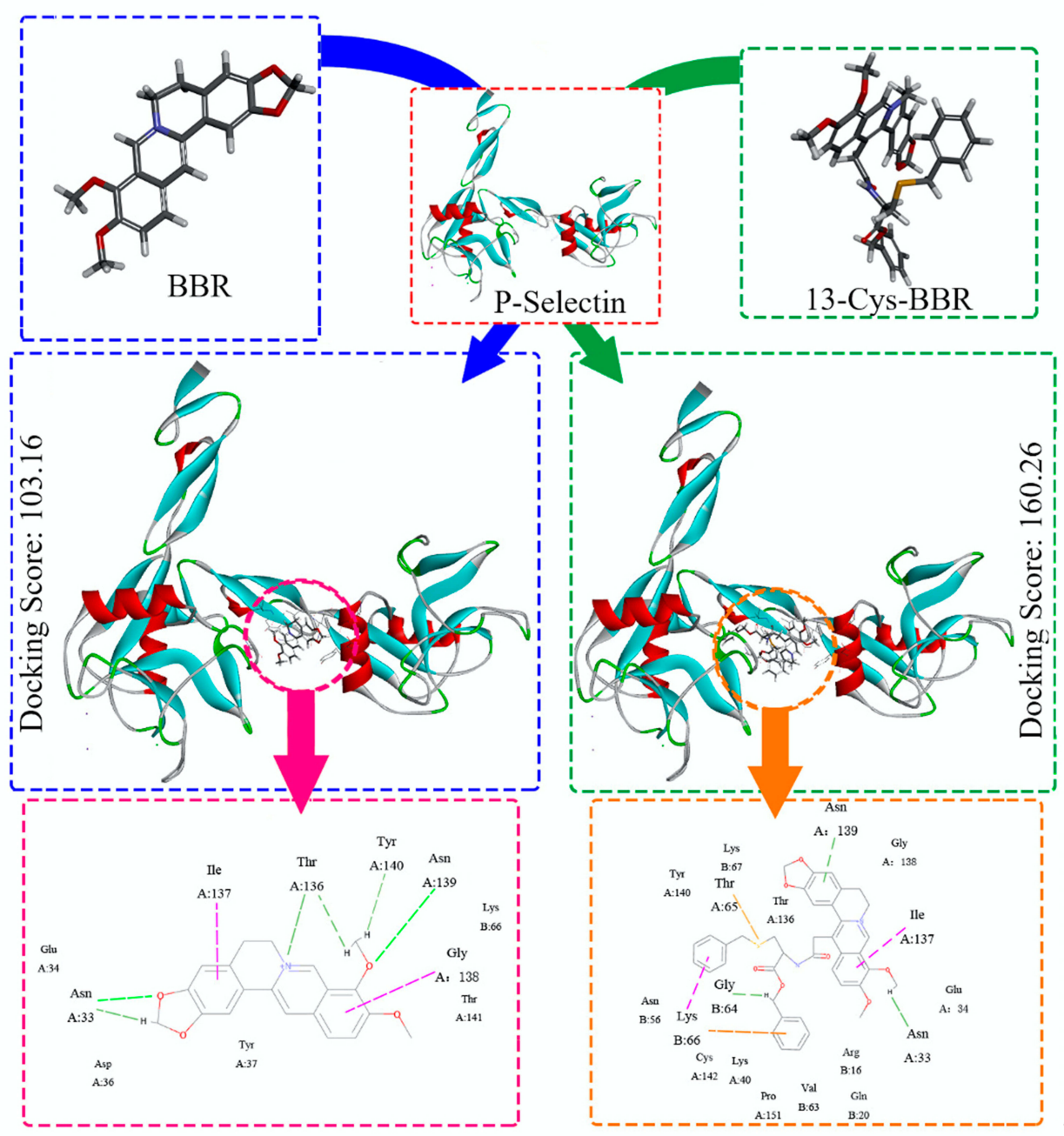

Figure 4 Docking feature of I3-Cys-BBR and BBR in the active site of P-selectin, as well as the docking scores of them. Abbreviations: BBR, berberine; I3-Cys-BBR, I3-[CH $\left.\mathrm{CH}_{2} \mathrm{CO}-\mathrm{Cys}(\mathrm{Bzl})-\mathrm{OBzl}\right]$-berberine.

\section{3-Cys-BBR Targets Arterial Thrombus}

To show whether 13-Cys-BBR targets thrombus of arterial thrombosis rats the ESI(+)-FT-ICR-MS spectra of the homogenate extracts of the thrombus, blood, brain, heart, kidney, liver and spleen of arterial thrombosis rats orally treated by CMC-Na (blank control) and $66.7 \mathrm{nmol} / \mathrm{kg}$ of 13-Cys-BBR were recorded. It was found that the ESI(+)FT-ICR-MS spectra of the homogenate extracts of the arterial thrombus, blood, brain, heart, kidney, liver and spleen of the rats treated by CMC-Na gave no ion peaks related to 13-Cys-BBR. Similarly, the ESI(+)-FT-ICR-MS spectra of the homogenate extracts of the blood, brain, heart, kidney, liver and spleen of the rats treated by 13Cys-BBR gave no any ion peaks related to 13-Cys-BBR.

Figure 5 is the ESI(+)-FT-ICR-MS spectrum of the homogenate extract of the arterial thrombus of the rats treated by 13-Cys-BBR, and 8 ion peaks including the ion peaks of 8-demethylation 13-Cys-BBR at 663.21058, 8.9-demethyl-13-Cys-BBR at 649.20030, 8.9-demethyl13-debenzyl-13-Cys-BBR at 573.16900, 8-demethylation 13-carbonylmethyl-BBR at 378.13360, 2.3-demethylene8,9-demethyl-13-Cys-BBR at 637.20030, BBR at 336.12302, 8-demethylation-BBR at 322.10738 and $\mathrm{CH}_{3}$ CO-Cys(Bzl)-OBzl at 343.12421 are observed. These ion peaks are locally amplified and inserted into Figure 5.

These ion peaks evidence that 13-Cys-BBR only enters into the arterial thrombus, releases 8-demethyl-13-CysBBR, 8.9-demethyl-13-Cys-BBR, 8.9-demethyl-13-debenzyl-13-Cys-BBR, 8-demethyl-13-carbonylmethyl-BBR, 2.3-demethylene-8,9-demethyl-13-Cys-BBR, BBR, 8-demethyl-BBR and $\mathrm{CH}_{3} \mathrm{CO}-\mathrm{Cys}(\mathrm{Bzl})-\mathrm{OBzl}$, thereby inhibits the formation of arterial thrombus. 


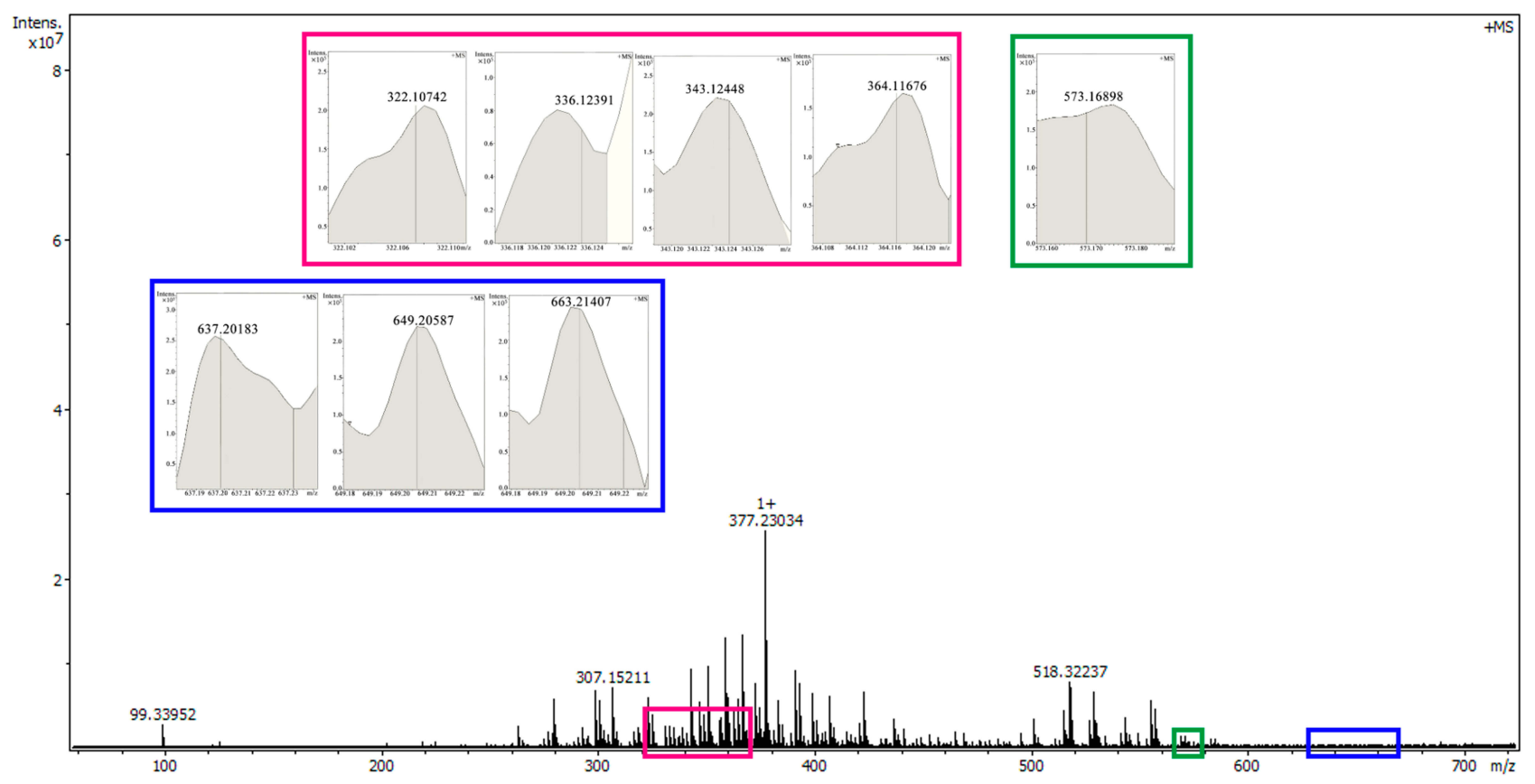

Figure $5 \mathrm{ESI}(+)$-FT-ICR-MS spectrum of the homogenate extract of the arterial thrombus of the rats treated by I3-Cys-BBR gave 8 ion peaks, the homogenate of the arterial thrombus was prepared and extracted by using the procedure of the literature. ${ }^{26}$

Abbreviation: 13-Cys-BBR, I3-[ $\left.\mathrm{CH}_{2} \mathrm{CO}-\mathrm{Cys}(\mathrm{Bzl})-\mathrm{OBz} \mid\right]-$-berberine.

\section{I3-Cys-BBR Targets Venous Thrombus}

To show whether 13-Cys-BBR targets thrombus of venous thrombosis rats the ESI(+)-FT-ICR-MS spectra of the homogenate extracts of the thrombus, blood, brain, heart, kidney, liver and spleen of the venous thrombosis rats treated by $\mathrm{CMC}-\mathrm{Na}$ (blank control) and 13-Cys-BBR were recorded. It was found that the ESI(+)-FT-ICR-MS spectra of the homogenate extracts of the thrombus, blood, brain, heart, kidney, liver and spleen of the venous thrombosis rats treated by $\mathrm{CMC}-\mathrm{Na}$ gave no ion peaks related to 13-Cys-BBR. Similarly, the ESI(+)-FT-ICR-MS spectra of the homogenate extracts of the blood, brain, heart, kidney, liver and spleen of the venous thrombosis rats treated by 13-Cys-BBR gave no ion peaks related to 13-Cys-BBR.

Figure 6 is the ESI(+)-FT-ICR-MS spectrum of the homogenate extract of venous thrombus of the rats treated by $13-\mathrm{Cys}-\mathrm{BBR}$, and 4 ion peaks including the ion peaks of 8-demethylation 13-Cys-BBR at 663.21058, 8-demethylation 13-carbonyl-methyl-BBR at 378.13108, 8-demethylation BBR at 322.10923 and $\mathrm{CH}_{3} \mathrm{CO}-\mathrm{Cys}(\mathrm{Bzl})-$ OBzl at 343.12502 are observed. These ion peaks are locally amplified and inserted into Figure 6.

These ion peaks evidence that 13-Cys-BBR only enters into the venous thrombus, released 8-demethylation 13-Cys-BBR, 8-demethylation 13-carbony
lmethyl-BBR, 8-demethylation $\mathrm{BBR}$ and $\mathrm{CH}_{3} \mathrm{CO}-\mathrm{Cys}$ (Bzl)-OBzl, thereby inhibits the formation of venous thrombus.

\section{I3-Cys-BBR Has No Liver and Kidney Toxicity}

To show the safety of 13-Cys-BBR health rats (240-270 g) were orally gave $10 \mathrm{~mL} / \mathrm{kg} /$ day of CMC-Na (blank control), $66.7 \mathrm{nmol} / \mathrm{kg} /$ day of 13-Cys-BBR and $66.7 \mathrm{nmol} / \mathrm{kg} /$ day of BBR (parent compound control) for 7 consecutive days. On the next day of the last dose the rats received ether anesthesia to sample arterial blood for testing serum uric acid (UA), serum alanine transaminase (ALT) and serum creatine kinase $(\mathrm{CK})$. Figure $7 \mathrm{~A}-\mathrm{C}$ shows that the serum UA, ALT and $\mathrm{CK}$ of the rats treated by $\mathrm{CMC}-\mathrm{Na}$ are equal to those of the rats treated by $13-\mathrm{Cys}-\mathrm{BBR}$, while the serum UA, ALT and $\mathrm{CK}$ of the rats treated by $\mathrm{CMC}-\mathrm{Na}$ are significantly lower than those of the rats treated by BBR. These data evidence that at $66.7 \mathrm{nmol} / \mathrm{kg}$ of oral dose 13-Cys-BBR, but not BBR, does not injure the liver and the kidney of the rats.

\section{Conclusion}

Based on the facts that there is a correlation between tumor and inflammation, the activity of 13-Cys-BBR slowing tumor growth is higher than that of BBR, and 


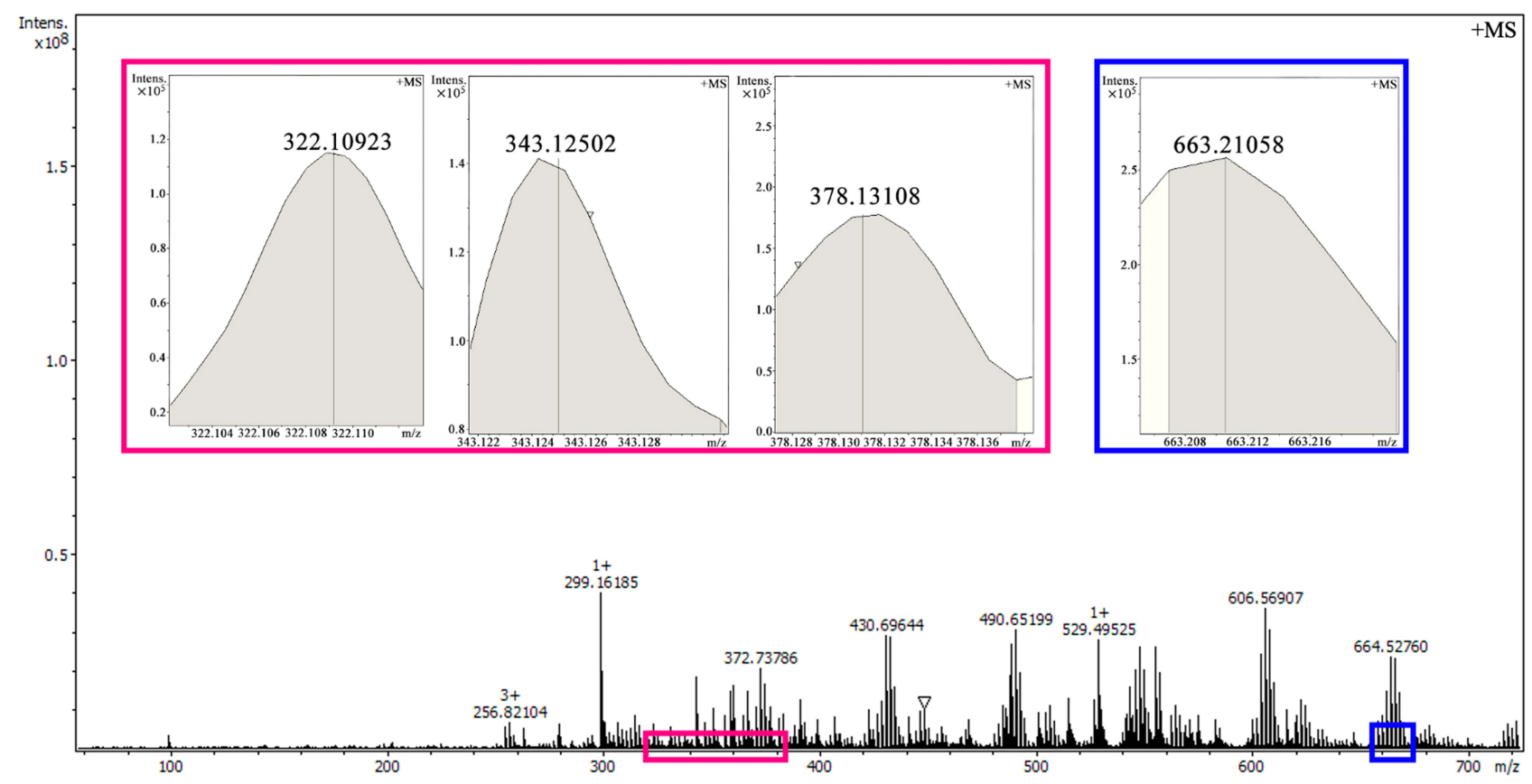

Figure $6 \mathrm{ESI}(+)$-FT-MS spectrum of the homogenate extract of the venous thrombus of the rats treated by 13-Cys-BBR gave 4 ion peaks, the homogenate of the venous thrombus was prepared and extracted by using the procedure of the literature. ${ }^{26}$

Abbreviation: 13-Cys-BBR, 13-[CH $\left.\mathrm{CH}_{2} \mathrm{CO}-\mathrm{Cys}(\mathrm{Bzl})-\mathrm{OBz} \mid\right]-$-berberine.

there is a correlation between thrombosis and inflammation. The activities of 13-Cys-BBR inhibiting thrombosis and inflammation were hypothesized been higher than those of BBR. The essential assays consistently evidence that 13 -Cys-BBR, but not BBR, is the excellent inhibitor of inflammation, venous thrombosis, arterial thrombosis, serum TNF-a and serum P-selectin. 13-Cys-BBR enters venous thrombus to release 8-demethyl-13-Cys-BBR, 8-demethyl-13-carb onylmethyl-BBR, 8-demethyl-BBR and $\mathrm{CH}_{3} \mathrm{CO}-$ $\mathrm{Cys}(\mathrm{Bzl})-\mathrm{OBzl}$; enters arterial thrombus to release
8-demethyl-13-Cys-BBR, 8.9-demethyl-13-Cys-BBR, 8.9-demethyl-13-debenzyl-13-Cys-BBR， 8-demethyl13-carbonylmethyl-BBR, 2.3-demethylene-8,9-dem ethyl-13-Cys-BBR, BBR, 8-demethyl-BBR and $\mathrm{CH}_{3}$ CO-Cys(Bzl)-OBzl. The release manner of 13-CysBBR targeting venous thrombus and arterial thrombus is summarized in Figure 8. The thrombus targeting leads 13-Cys-BBR having no liver and kidney toxicity as well.

The impact of arterial thrombosis and venous thrombosis on the outcome of the cancer patients is well
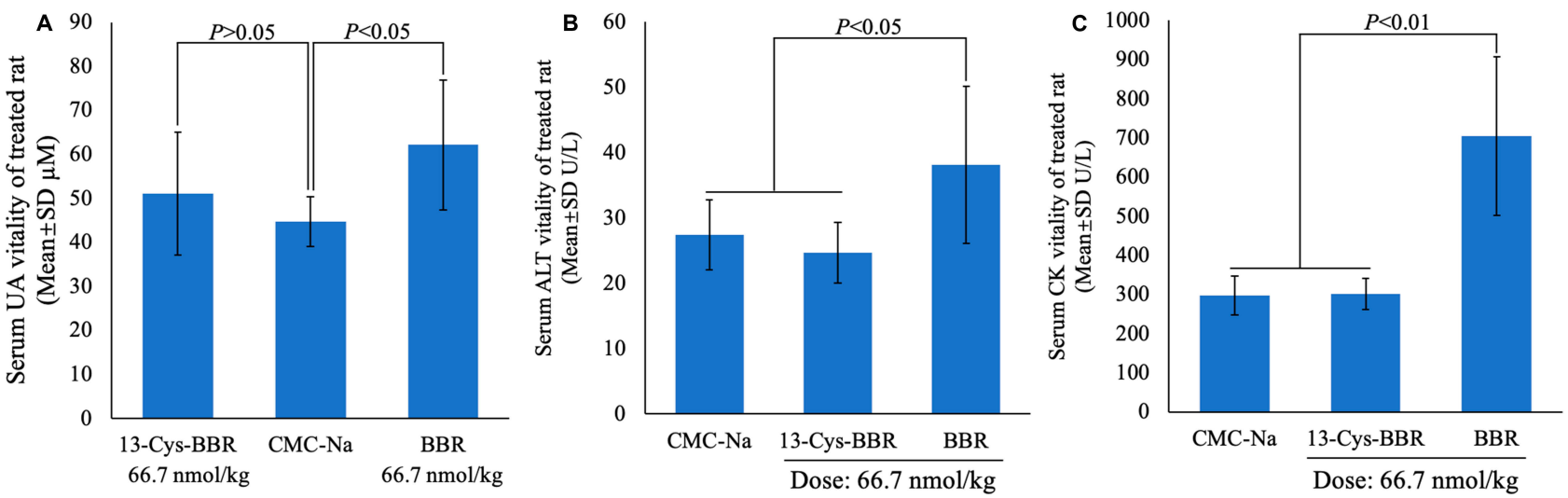

Figure 7 Liver and kidney toxicity of I3-Cys-BBR and BBR in vivo: (A) effect of I3-Cys-BBR and BBR on serum UA of health rats, $n=3$; (B) effect of I3-Cys-BBR and BBR on serum $A L T$ of health rats, $n=3$; (C) effect of I3-Cys-BBR and BBR on serum $C K$ of health rats, $n=3$.

Abbreviations: BBR, berberine; I3-Cys-BBR, I3-[ $\mathrm{CH}_{2} \mathrm{CO}-\mathrm{Cys}(\mathrm{Bzl})-\mathrm{OBz}$ ]-berberine; UA, uric acid; ALT, alanine transaminase; CK, creatine kinase. 


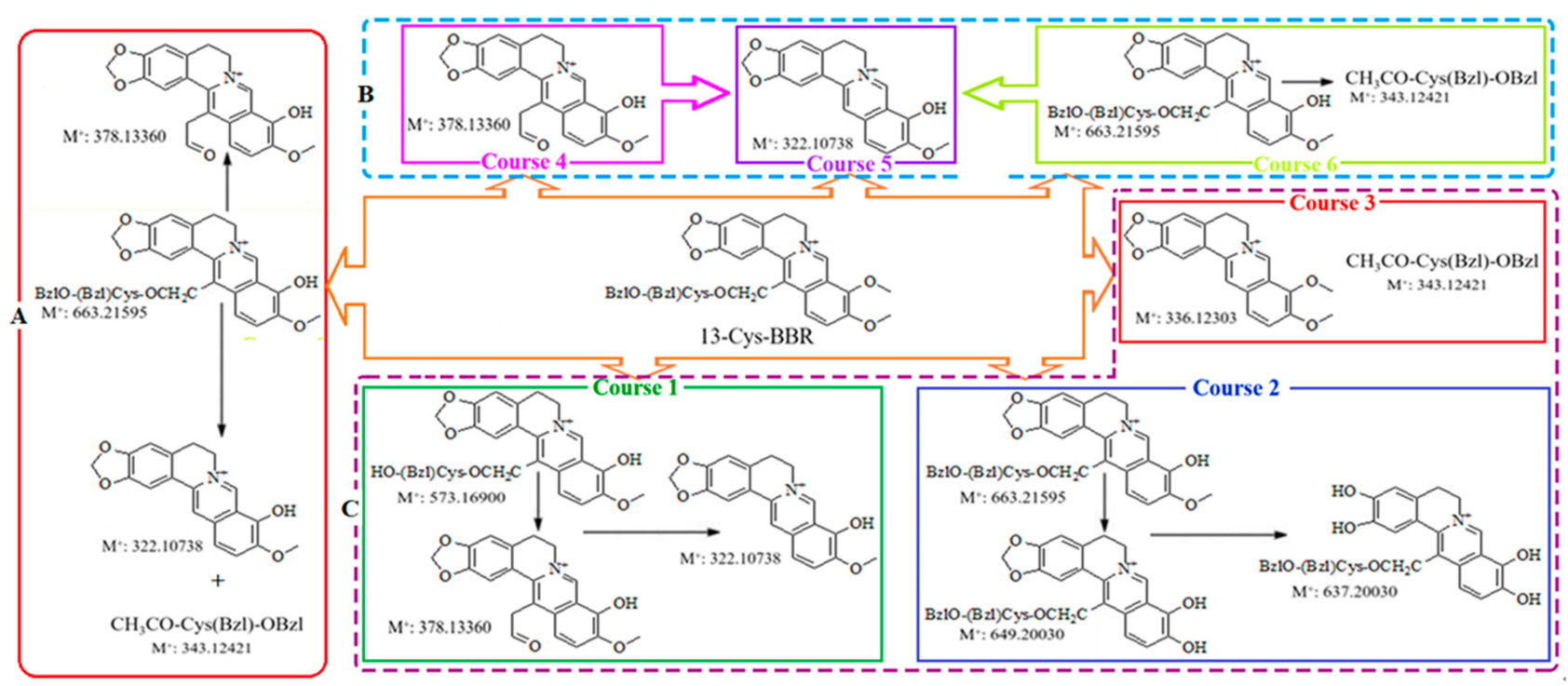

Figure 8 Thrombus targeting action and release of 13-Cys-BBR in vivo: (A) venous thrombus targeting action and release of I3-Cys-BBR; (B \& C) arterial thrombus targeting action and release of I3-Cys-BBR.

Abbreviations: BBR, berberine; I3-Cys-BBR, I3-[CH $\left.\mathrm{CH}_{2} \mathrm{CO}-\mathrm{Cys}(\mathrm{Bz})-\mathrm{OBz} \mid\right]$-berberine.

established. $^{24,26-29}$ And the thrombotic research is often linked to inflammatory response. ${ }^{30,31}$ The biological findings of 13-Cys-BBR in the present paper with the effect of arterial and venous thrombosis on the outcome of the cancer patients together suggest that 13-Cys-BBR should be a promising preclinical candidate.

\section{Acknowledgment}

The authors thank the Special Project of China (2018ZX097201003), NSFC (81673303 and 81572779), BNSF (7172028) and KM201810025010 for financial supports.

\section{Disclosure}

The authors report no conflicts of interest in this work.

\section{References}

1. Wang N, Tan H-Y, Li L, Yuen M-F, Feng Y. Berberine and coptidis rhizoma as potential anticancer agents: recent updates and future perspectives: recent updates and future perspectives. J Ethnopharmacol. 2015;176:35-48. doi:10.1016/j.jep.2015.10.028

2. Yang -S-S, Yu C-B, Luo Z, et al. Berberine attenuates sodium palmitate-induced lipid accumulation, oxidative stress and apoptosis in grass carp(Ctenopharyngodon idella)hepatocyte in vitro. Fish Shellfish Immunol. 2019;88:518-527. doi:10.1016/j.fsi.2019.02.055

3. Ren K, Zhang W, Wu G, et al. Synergistic anti-cancer effects of galangin and berberine through apoptosis induction and proliferation inhibition in oesophageal carcinoma cells. Biomed Pharmacother. 2016;84:1748-1759. doi:10.1016/j.biopha.2016.10.111

4. Hu S, Chen C-W, Chen S-T, et al. Inhibitory effect of berberine on interleukin-2 secretion from PHA-treated lymphocytic jurkat cells. Int Immunopharmacol. 2019;66:267-273. doi:10.1016/j.intimp.20 18.11 .020
5. Chang Y-P, Huang C-C, Shen C-C, et al. Differential inhibition of CYP1-catalyzed regioselective hydroxylation of estradiol by berberine and its oxidative metabolites. Drug Metab Pharmacokinet. 2015;30(5):374-383. doi:10.1016/j.dmpk.2015.08.006

6. Naveen CR, Gaikwad S, Agrawal-Rajput R. Berberine induces neuronal differentiation through inhibition of cancer stemness and epithelial-mesenchymal transition in neuroblastoma cells. Phytomedicine. 2016;23(7):736-744. doi:10.1016/j.phymed.20 16.03.013

7. Stein DJ, Khoo J-P, Ahokas A, et al. 12-week double-blind randomized multicenter study of efficacy and safety of agomelatine $(25-50 \mathrm{mg} /$ day $)$ versus escitalopram $(10-20 \mathrm{mg} /$ day) in out-patients with severe generalized anxiety disorder. Eur Neuropsychopharm. 2018;28(8):970-979. doi:10.1016/j.euroneuro.2018.05.006

8. Kumar A, Chopra K, Mukherjee M, Pottabathini R, Dhull DK. Current knowledge and pharmacological profile of berberine: an update. Eur J Pharmacol. 2015;761:288-297. doi:10.1016/j. ejphar.2015.05.068

9. Yu Y, Hao G, Zhang Q, et al. Berberine induces GLP-1 secretion through activation of bitter taste receptor pathways. Biochem Pharmacol. 2015;97(2):173-177. doi:10.1016/j.bcp.2015.07.012

10. Lang S, Popp T, Kriegs CS, et al. Anti-apoptotic and moderate anti-inflammatory effects of berberine in sulfur mustard exposed keratinocytes. Toxicol Lett. 2017;293:2-8. doi:10.1016/j. toxlet.2017.09.004

11. Luganini A, Mercorelli B, Messa L, Palù G, Gribaudo G, Loregian A. The isoquinoline alkaloid berberine inhibits human cytomegalovirus replication by interfering with the viral Immediate Early-2 (IE2) protein transactivating activity. Antiviral Res. 2019;164:52-60. doi:10.1016/j.antiviral.2019.02.006

12. Hashemi-Niasari F, Rabbani-Chadegani A, Razmi M, Fallah S. Synergy of theophylline reduces necrotic effect of berberine, induces cell cycle arrest and PARP, HMGB1, Bcl-2 family mediated apoptosis in MDA-MB-231 breast cancer cells. Biomed Pharmacother. 2018;106:858-867. doi:10.1016/j.biopha.2018.07.019

13. Zhang H, Shan Y, Wu Y, et al. Berberine suppresses LPS-induced inflammation through modulating Sirt1/NF- $\mathrm{KB}$ signaling pathway in RAW264.7 cells. Int Immunopharmacol. 2017;52:93-100. doi:10.1016/j.intimp.2017.08.032 
14. Wang Y, Zhang S. Berberine suppresses growth and metastasis of endometrial cancer cells via miR-101/COX-2. Biomed Pharmacother. 2018;103:1287-1293. doi:10.1016/j.biopha.2018.04.161

15. Tsang CM, Pan Cheung KC, Cheung YC, et al. Berberine suppresses Id-1 expression and inhibits the growth and development of lung metastases in hepatocellular carcinoma. Biochim Biophys Acta. 2015;1852(3):541-551. doi:10.1016/j.bbadis.2014.12.004

16. Li Y-H, Xiao H-T, Hu D-D, et al. Berberine ameliorates chronic relapsing dextran sulfate sodium-induced colitis in C57BL/6 mice by suppressing Th17 responses. Pharmacol Res. 2016;110:227-239. doi:10.1016/j.phrs.2016.02.010

17. Li J-W, Yuan K, Shang S-C, Guo Y. A safer hypoglycemic agent for type 2 diabetes - berberine organic acid salt. J Funct Foods. 2017;38 (Pt A):399-408. doi:10.1016/j.jff.2017.09.031

18. Wong SK, Chin K-Y, Ima-Nirwana S. Berberine and musculoskeletal disorders: the therapeutic potential and underlying molecular mechanisms. Phytomedicine. 2019;13:152892.

19. Popiołek I, Niziołek A, Kamiński K, Kwolek U, Nowakowska M, Krzysztof S. Cellular delivery and enhanced anticancer activity of berberine complexed with a cationic derivative of $\gamma$-cyclodextrin. Bioorg Med Chem. 2019;27(7):1414-1420. doi:10.1016/j. bmc.2019.02.042

20. Jiao Hao M, Li Y, Liu L, et al. The design and synthesis of a novel compound of berberine and baicalein that inhibits the efficacy of lipid accumulation in 3T3-L1 adipocytes. Bioorg Med Chem. 2017;25 (20):5506-5512. doi:10.1016/j.bmc.2017.08.013

21. Li Y-H, Zhang M, Fu H-B, Xiao H-T, Bian Z-X. Pre-clinical toxicity of a combination of berberine and 5-aminosalicylic acid in mice. Food Chem Toxicol. 2016;97:150-158. doi:10.1016/j.fct.2016.08.031

22. Gupta L, Sharma AK, Gothwal A, et al. Dendrimer encapsulated and conjugated delivery of berberine: a novel approach mitigating toxicity and improving in vivo pharmacokinetics. Int J Pharm. 2017;528 (1-2):88-99. doi:10.1016/j.ijpharm.2017.04.073

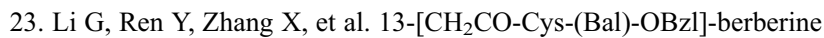
exploring the correlation of anti-tumor efficacy with ROS and apoptosis protein. Onco Targets Ther. 2019;12:10651-10662. doi:10.2147/ OTT.S231035

24. Liu W, Mao Y, Zhang X, et al. RGDV-modified gemcitabine: a nano-medicine capable of prolonging half-life, overcoming resistance and eliminating bone marrow toxicity of gemcitabine. Int J Nanomedicine. 2019;14:7263-7279. doi:10.2147/IJN.S212978

25. Suleman A, Jarvis V, Hadziomerovic A, Carrier M, McDiarmid S. Implanted vascular access device related deep vein thrombosis in oncology patients: a prospective cohort study. Thromb Res. 2019;177:117-121. doi:10.1016/j.thromres.2019.02.033

26. Chen H, Lu A, Zhang X, et al. Design and development of ICCA as a dual inhibitor of GPIIb/IIIa and P-selectin receptors. Drug Des Devel Ther. 2018;12:2097-2110. doi:10.2147/DDDT.S169238

27. Otani K, Ishihara S, Hata K, et al. Colorectal cancer with venous tumor thrombosis. Asian J Surg. 2018;41(3):197-202. doi:10.1016/j. asjsur.2016.07.013

28. Liu S, Zhang F, Xie L, et al. Machine learning approaches for risk assessment of peripherally inserted central catheter-related vein thrombosis in hospitalized patients with cancer. Int J Med Inform. 2019;129:175-183. doi:10.1016/j.ijmedinf.2019.06.001

29. Farge D, Le Maignan C, Doucet L, Frere C. Women, thrombosis, and cancer. Thromb Res. 2019;181(Suppl 1):S47-S53. doi:10.1016/ S0049-3848(19)30367-6

30. Lee J, Jackman JG, Kwun J, et al. Nucleic acid scavenging microfiber mesh inhibits trauma-induced inflammation and thrombosis. Biomaterials. 2017;120:94-102. doi:10.1016/j.biomaterials.2016.1 2.024

31. Amani H, Habibey R, Shokri F, et al. Selenium nanoparticles for targeted stroke therapy through modulation of inflammatory and metabolic signaling. Sci Rep. 2019;9(1):6044. doi:10.1038/s41598019-42633-9
Drug Design, Development and Therapy

\section{Publish your work in this journal}

Drug Design, Development and Therapy is an international, peerreviewed open-access journal that spans the spectrum of drug design and development through to clinical applications. Clinical outcomes, patient safety, and programs for the development and effective, safe, and sustained use of medicines are a feature of the journal, which has also been accepted for indexing on PubMed Central. The manuscript management system is completely online and includes a very quick and fair peer-review system, which is all easy to use. Visit http://www. dovepress.com/testimonials.php to read real quotes from published authors. 